\title{
A LIBERDADE À LUZ DO PRINCÍPIO VIDA DE HANS JONAS
}

Liberty in light of the phenomenon of life by Hans Jonas

Sylvia Valéria Pinheiro Graduanda em Filosofia/UFRJ

Graduada em Direito/UFRJ

RESUMO: A liberdade aparece em Hans Jonas (1903-1993) como diretriz para a compreensão da vida, serve lhe como pilar na formulação de seu Princípio Vida. Ao explorar a relação entre a necessidade natural e a contingência radical, apontando para a estrita hegemonia da lei da causalidade da ação. Apesar da pluralidade de possibilidades, uma vez encetado o caminho, as possibilidades passadas deixam de existir. A Teoria da Evolução de Darwin (1809-1882) revela a contingente interação entre organismo e meio ambiente. Por parte do organismo ocorrem as variações aleatórias e o ambiente atua pela seleção natural. Jonas aplica o conceito de liberdade na tarefa de interpretar a vida e a considera como o seu fio condutor, pois diferentes estágios da substância Vida podem ser compreendidos se tomado por foco a liberdade a ele disponível. O Ser tende a graus cada vez mais elevados de interação, que implicam, evidentemente, em mais possibilidades de liberdade. No entanto esta liberdade está imbricada com a necessidade do Ser que urge por satisfação. Assim, se conforma um vigoroso movimento dialético: a necessidade demanda uma satisfação do exercício de uma liberdade. Esse binômio se autossustenta, um não existe sem o outro, e nesse movimento incessante o Ser existe. Nas palavras de Hans Jonas, "o poder se transforma em dever quando o que importa é o ser" (JONAS, 2004)

PALAVRAS-CHAVES: Liberdade; Princípio Vida; Hans Jonas. 
A liberdade aparece em Hans Jonas (1903-1993) como diretriz para a compreensão da vida, serve the como pilar na formulação de seu Princípio Vida. Os matizes com que a liberdade se apresenta tecem o fino entendimento das diversas manifestações de vida em todos os seres, até a culminância da expressão da vida no ser humano. O presente texto buscará seguir esse fio pela tessitura da obra Princípio Vida do autor.

\title{
TEORIA DA EVOLUÇÃO
}

A cosmologia de Newton-Laplace, graças a revolução copernicana - que mostrou não haver ponto privilegiado no universo -, revelou em suas equações e fórmulas uma relação entre a necessidade natural e a contingência radical, apontando para a estrita hegemonia da lei da causalidade da ação.

As coisas e os eventos para serem eles mesmos só poderiam ocorrer da maneira que ocorreram. Apesar da pluralidade de possibilidades, uma vez encetado o caminho, as possibilidades passadas deixam de existir:

\begin{abstract}
Embora tudo quanto acontece nesta interação seja governada pela lei da causalidade, as estruturas resultantes são metafisicamente contingentes: nenhuma delas realiza um fim especial da realidade, uma vez que na aritmética das grandezas que se adicionam umas às outras a realidade não tem nenhuma preferência interna por este resultado em comparação com qualquer outro. Portanto a necessidade extrema desta soma é o correlato da mais radical das contingências de todo ser particular. Se algumas das condições iniciais tivessem sido diferentes, o sistema solar não existir, ou teria uma composição diferente da que efetivamente tem, e a completude da natureza como sistema em equilíbrio não sofreria prejuízo. (JONAS, 2004, p 59)
\end{abstract}

A Teoria da Evolução revela a contingente interação entre organismo e meio ambiente: cada um detém uma parcela do ser que veio-a-ser, o primeiro pelas variações aleatórias de suas escolhas de interação e o segundo pela seleção natural dessas escolhas.

A eventual liberdade do organismo de escolher não interagir com o meio, implicaria em ausência de vida. Assim, a vida demanda, necessariamente, interação com o meio. Por outro lado, a interação, que se viu ser contingente à vida, não garante a sua manutenção, pois o meio, pela seleção natural, pode rejeitar a escolha do organismo.

Somente por um enfoque analítico mnemônico se podem verificar as diversas possibilidades que antecederam a escolha determinante de um ser atual. As liberdades das ações 
pretéritas daquele ser, se exercidas de outra forma provocariam a ocorrência de outro ser diverso do atual e, portanto, e implicaria na não existência do ser atual.

A liberdade de escolha do organismo é infinita, mas só algumas delas serão capazes de mantê-lo na vida, na forma que ele se encontra.

\section{LIBERDADE DIALÉTICA}

Liberdade é o fio condutor da vida. Os diferentes estágios da Vida podem ser compreendidos se tomado por foco a liberdade a ele disponível.

Hans Jonas remonta a um termo a quo da vida, um marco zero, onde a substância se imbui de um vir-a-ser-em-si saltando para o mundo das substâncias vivas, motivada por uma incipiente interioridade "pré-histórica" da vida:

Uma vez que a vida, tendo interioridade e finalidade, originou-se do substrato material do mundo, tais qualidades não lhe podem ser estranhas em sua essência; e se não o podemos em sua essência, então (aqui o argumento tornase cosmogônico) também não o podemos em sua origem: já desde a matéria em formação na explosão primordial deve ter estado presente a possibilidade da subjetividade - a dimensão interior em latência, que esperou sua oportunidade externa no cosmos para se manifestar. Algumas conjecturas vão além disso e tentam pensar essa própria "espera" (entendida, por exemplo, como uma "aspiração"), que participa no desenvolvimento das condições físicas para o seu cumprimento, algo como uma teleologia secreta presente em meio à colossal predominância das coincidências mecânicas na pré-história cósmica da vida. Nessa mesma direção, eu mesmo também formulei a conjectura cosmogônica de um fator "desejante" orientado por fins como estando já presente na origem primordial das coisas. (JONAS, 2010 p. 40)

Desse ponto em diante as liberdades se somam e se tornam cada vez mais amplas, perfazendo um efeito cumulativo, umas sobre as outras, sempre se ampliando.

Assim, Jonas aplica o conceito de liberdade na tarefa de interpretar a vida, que é o mister de sua obra.

O Ser tende a graus cada vez mais elevados de interações com o meio, que significa um número cada vez maior de possibilidades, as quais implicam, evidentemente, em mais possibilidades de liberdade. No entanto esta liberdade estána necessidade do Ser que urge por satisfação. Assim, se conforma um vigoroso movimento dialético: a necessidade demanda para uma satisfação do exercício de uma liberdade. Esse binômio se autossustenta, um não existe sem o outro, e nesse movimento incessante o Ser existe, ese faz Forma Viva.

Nas palavras de Hans Jonas, "o poder se transforma em dever quando o que importa é o ser" (JONAS, 2004, p 107) 


\section{O SI-MESMO E O MUNDO}

A vida se apossa de substâncias (substratos) e as liberta no mundo, se fazendo Forma Viva. Esta seria a primeira liberdade ontológica.

Assim, a Forma Viva está livre ela não se identifica com o substrato que a libertou do mundo e que passou a constituí-la.

A existência da Forma Viva depende da matéria, a qual está no mundo, a vida necessita da matéria para se manter na forma, ela necessita possuir o mundo, continuadamente (Necessidade Biológica).

Liberdade ontológica (liberdade formal da matéria) e necessidade biológica conformam dois pólos de uma espiral cada vez mais ampla onde uma se lança a outra, numa dinâmica que possibilita tornar o mundo presente em si. Esta transcendência da necessidade sobre a matéria, aponta para um fora:

Neste autotranscender através da condição de necessidade fundamenta-se a transcendência essencial de toda vida, que nos estágios mais elevados lhe abre um mundo cada vez mais amplo. O ser-dependente indica o campo de suas possíveis realizações, desta maneira criando a intencionalidade como caráter básico de toda vida. (JONAS, 2004, p 109)

"A identidade de si mesmo é um caráter ontológico dos seres vivos sempre em exercício diante da contínua modificação da matéria" (MOURA, 2012, p 36). Esse processo se dá primordialmente pelo metabolismo.

\section{AMPLIAÇÃO DA LIBERDADE}

Jonas analisa a relação dos sentidos físicos com a liberdade. Quanto mais refinados os sentidos, maior o ângulo de liberdade do organismo. A visão é o sentido de excelência das Formas Vivas e no ser humano é a condição de possibilidade de sua evolução espiritual na medida em que enseja a produção de imagens. Segundo Jonas, a capacidade imagética apresenta três características: "1) simultaneidade na apresentação de uma variedade, 2) neutralização da cauda da afecção do sentido, 3) distância no sentido espacial e espiritual” (JONAS, 2004, p 160).

Simultaneidade está na imediata apreensão pelo sentido da visão de tudo que é visto em um abrir de olhos. A parcela do mundo avistada se presentifica em todas as suas nuances num átimo, apartado do tempo. Nenhum outro sentido se liberta dos grilhões da dimensão temporal como a visão, pois os demais sentidos dependem do corpo ser afetado por um período de tempo para que ocorram.

A sensação tem que se prolongar, para com seu fluir adicionar a sequência àquilo que foi iniciado no que antecede (...) $\mathrm{O}$ som existe como sequência, cada momento dele desaparece no que já passou enquanto ele continua a doar (...) 
No caso do tato a situação é semelhante, só que aqui a sucessão é mais um processo de realização ativa do que uma mera recepção passiva de dados" (JONAS, 2004, p 168).

A dimensão temporal é apropriada pela visão, na medida em que "na presença visível de objeto, o espectador pode repousar e desfrutar de um agora ampliado" (JONAS, 2004, p 168) e apenas pela modificação do conjunto visado que novamente ele é fisgado pelo tempo.

Além disso, soma-se ao valor da simultaneidade da visão, a possibilidade da mirada de um mundo externo "ainda sem comunicação com o ser vivo" que habilita o animal a escolher o seu agir, constituindo enorme vantagem nesse caleidoscópio das interações com o meio ambiente.

A segunda característica da visão, neutralidade das causas da afetação dos sentidos, é de importância ímpar considerando que o arcabouço do pensamento jonasiano está na radical aplicação da lei da causalidade da ação. Dessa forma, um sentido que propicie ao ser se manter fora desta lei, ou pelo menos retardá-la, constitui outra enorme vantagem. $\mathrm{Na}$ visão, o ver não atinge o objeto visto, nem demanda nenhuma modificação na situação vista:

Eu não preciso fazer outra coisa senão olhar - sem que por isso o objeto seja tocado; e tão logo haja luz, o objeto só precisa estar aí para tornar-se visível e eu não sou tocado por isso: e no entanto meu estar-em-mim o percebe no seu estar-me-si, ele me está presente sem que me atraia para sua presença (JONAS, 2004, p 170).

A terceira característica da visão, apontada por Hans Jonas, o distanciamento espacial, dessa tríade relaciona mais amiúde com a anterior, pois, quanto mais distante, mais neutra a visão se dá. Além disso, a boa visão exige o distanciamento correto, o que varia de acordo com o objeto visado.

Por outro lado, ainda que a visão seja eminentemente estática, paradoxalmente, o movimento está enraizado em sua origem. Não só quanto ao evidente movimento muscular que ela demanda (retração e distensão do aparelho ótico, movimento do globo ocular), mas na “dependência da perspectiva ótica em relação a locomoção” (JONAS, 2004, p 179).

Graças às experiências de movimento que o ser humano empreende no mundo, ora seguindo em uma ou outra direção, ora avançando ou recuando, interagindo o seu próprio corpo com os corpos do mundo, ele cria "autoperpecção cinestésica" da atividade motora que o guia nas sucessivas construções de distância.

Desta forma aparelhado, o ser humano pode, efetivamente, se entregar ao deleite contemplativo, livremente:

Uma vez de posse do conhecimento que me foi deixado por estas experiências de movimento, eu também posso efetivamente observar o mundo a partir de minha posição de repouso, e compreendê-lo em perspectiva e na ordem de suas diferentes direções. Então eu posso ser o observador estacionário e inativo, que deixa o espetáculo do mundo desfilar diante de seus olhos como em uma tela (JONAS, 2004, p 180). 
Enquanto os vegetais estão adstritos ao que lhes é sensível pelo tato, os animais dispõem de um aparelho sensorial muito mais amplo. Jonas eleva a mobilidade à condição de máxima importância dos sentidos:

E o exemplo do sentido que parecer ser o mais livre de tal mistura mostra que a mobilidade, que é necessária para o próprio exercício da percepção sensitiva, participa, por sua vez da experiência básica da sensibilidade, na medida em que está deve ser mais do que um mero registro de estímulos exteriores (JONAS, 2004, p 180).

O movimento confere o atributo da liberdade aos sentidos. $\mathrm{O}$ animal ao escolher se movimentar para uma direção ou outra, parar ou voltar, escolhe como e quais sensações desejam se afetar.

\section{LIBERDADE DA IMAGEM}

Assim como o movimento, a imagem é produzida em uma escala muito maior do exercício da liberdade. "A linguagem e a capacidade simbólica são modos de ser exclusivos do ser humano" (MOURA, 2012, p 36). A imagem presentifica no homem a ausência, é a presença imagética do fisicamente ausente (cf. MOURA, 2012, p 36).

A imagem é diferente da coisa imaginada, sob pena de perder seu status de imagem e passar a ser a própria coisa ou outra coisa. Portanto, em cada passo na construção da imagem o homem escolhe o que será omitido e quais elementos serão representados.

Hans Jonas associa a capacidade imagética a primazia do sentido da visão, constituindo uma maneira de ser dá visão.

Destarte, o homem se sobressai da totalidade nos organismos vivos, por fazer a junção desses foi atributos: movimento e imaginação. O movimento é orientado pela imaginação e essa dinâmica revela a maior liberdade da espécie humana.

\section{CONCLUSÃO}

Por tudo, se pode dizer que a liberdade é um agir para fora de si, seja para se apropriar do que está fora, seja para alterar o que está fora, o mundo.

A liberdade é facilmente percebida como uma contraparte da necessidade desde o mais simples dos organismos. O metabolismo é o mais simples exercício dessa liberdade. O comer e o excretar são exercício da liberdade absolutamente contingente. 
A filosofia de Jonas parece afirmar que a Vida está em constante busca por liberdade, ideia que ele corrobora com a Teria Evolucionista de Darwin.

No entanto, a cada ampliação do diâmetro do arco da liberdade, surge o incremento proporcional da necessidade. E um organismo necessitado é um organismo frágil.

Assim, o homem aparece como o mais livre e o mais frágil de todas as espécies.

Essa flagrante fragilidade do homem, talvez seja o que acarreta a enorme produção cultural e tecnológica e as tensões pessoais entre si e as demais espécies.

A força motriz do agir do homem está assentada nessa busca incessante de suprir a necessidade pelo exercício da liberdade. Nas palavras pulsantes de Nietzsche:

Exigir da força que não se expresse como força, que não seja um quererdominar, um querer-vencer, um querer-subjulgar, uma sede de inimigos, resistências e triunfos, é tão absurdo quanto exigir da fraqueza que se expresse como força (NIETZSCHE, 2009, pp 32-33). 


\section{BIBLIOGRAFIA:}

JONAS, Hans. O Princípio Vida. Petrópolis: Vozes, 2004.

JONAS, Hans. Matéria, Espírito e Criação. Petrópolis: Vozes, 2010.

MOURA, Sarah. Sobre a Filosofia da Vida, de Hans Jonas. Rio de Janeiro: UFRJ, 2012. (Monografia de Graduação).

NIETZSCHE, Friedrich. Genealogia da Moral. São Paulo: Companhia das Letras, 2009. 